\title{
Rugby as a rehabilitation program in a United Kingdom Male Young Offenders' Institution: key findings and implications from mixed methods research
}

\author{
Sarah Welland, Linda J. Duffy, Bahman Baluch* \\ School of Science and Technology, Middlesex University, London, UK
}

There is a growing body of research on the effectiveness of rehabilitation programs in a Young Offenders' Institution (YOI). The aim of the present study is to investigate the effectiveness of rugby training as a rehabilitation intervention in a $\mathrm{YOI}$ in the United Kingdom. Young adult males $(n=46)$ currently serving sentences at the $Y O$ I were split into two groups, intervention ( $n=25$; mean age, $19.64 \pm 0.81$ years) and no intervention ( $n=21$; mean age, $19.76 \pm 0.89$ ). Participants completed the Criminal Attitudes and Associates (MCAA) instrument at three different time cycles and then pre/post for intervention group. Additionally, qualitative interviews (one to one and focus groups) were carried out with the intervention and no intervention groups during the same cycles of the study. The results of questionnaire analysis showed no significant difference in MCAA measures taken before and after rugby intervention.
Interestingly, the intervention group showed more pro-criminal attitudes on their responses compared to the no intervention group. Finally, analysis of the 3 cycles of data collected showed that the time of the year the questionnaire was completed has a significant impact on the responses given. In contrast, the qualitative interviews showed a very positive change of attitude towards rehabilitation from the intervention group after rugby training. The implications of the results in relation to studies aimed at evaluation of the intervention programs in $\mathrm{YOI}$ are discussed.

Keywords: Young offenders, Rugby, Rehabilitation, Pro-criminal attitudes, Mixed methods

\section{INTRODUCTION}

In recent years a realisation has occurred regarding the significant issue in the United Kingdom with reoffending, with rates of recidivism within the young adult population among the highest in the prison estate. The Ministry of Justice have reported the reoffending rate specifically for young adult offenders (18-20-year olds) as 30\%. Young adults in prison have a variety of physical, mental and emotional needs (Meek and Lewis, 2012) which can impact their access to certain rehabilitation opportunities, ultimately informing their path to release and potential to reoffend. This calls for a need to understand offending behaviors and factors that may predict or prevent reoffending, as well as an understanding of how these can be addressed, if rehabilitation is to be suc- cessful.

In line with the increasing number of interventions being provided in prisons to meet rehabilitation needs, recent research has examined the social, psychological and health benefits of prisonbased programs which include those focusing on arts, horticulture and vocational activities (Farrier et al., 2019; Wilkinson and Caulfield, 2017). The majority of these studies have demonstrated benefits in quality of life and reduced anxiety, depression and stress (Battaglia et al., 2013) as well as reduced rates of recidivism (Proctor et al., 2012).

A growing body of research has also explored the use of sport as a tool for youth rehabilitation. Participation in school sport clubs has been seen to contribute to fostering positive and desirable attitudes (Kwon, 2018) and support the development of social skills
${ }^{*}$ Corresponding author: Bahman Baluch (iD https://orcid.org/0000-0003-0650-4421 School of Science and Technology, Middlesex University, London, UK E-mail: B.Baluch@mdx.ac.uk

Received: November 1, 2019 / Accepted: December 27, 2019
This is an Open Access article distributed under the terms of the Creative Commons Attribution Non-Commercial License (https://creativecommons.org/licenses/by-nc/4.0/) which permits unrestricted non-commercial use, distribution, and reproduction in any medium, provided the original work is properly cited. 
and self-esteem (Bailey, 2006). Team sport in particular has been demonstrated to develop social cohesion and enjoyment (Elbe et al., 2017) and the potential for using this in the rehabilitation of offenders in a custodial setting has been explored in recent literature. Sport in prison has been seen to have a positive effect on the psychological, social and physical wellbeing of offenders (Amtmann and Kukay, 2016; Battaglia et al., 2013). A small amount of studies have investigated the use of contact sport with youths, for example the effect of martial arts on improving wellbeing outcomes including resilience and self-efficacy (Moore et al., 2018). The unique impact of utilising a full-contact team sport such as rugby in a prison setting as a mechanism for addressing and improving attitudes towards offending however, has yet to be explored to any great extent.

Attitudes favoring criminal activity have been established as a predictor of antisocial behavior in offender populations (Mills et al., 2004) and previous studies have examined the relationship between pro-criminal attitudes and recidivism in offenders (Walters, 2005). Findings implicating these attitudes as among the strongest predictors of male adult offender recidivism have led to the development of intervention methods aiming to address pro-criminal attitudes. Such cognitive based programs have seen a significant reduction in post intervention criminal attitude scores (Simourd et al., 2016; Warner et al., 2018).

Researchers have also examined the relationship between criminal attitudes and criminal associates, finding that the proportion of free time spent with criminal associates statistically predicted criminogenic thinking (Whited et al., 2017). The notion of criminal associates as a dynamic risk factor for crime has been operationalised in intervention measures such as the Measure of Criminal Attitudes and Associates (MCAA) (Mills et al., 2002). Research has included the use of this tool with sexual and violent offenders (Mills et al., 2003; Mills et al., 2004) and found it a valid and reliable instrument in predicting general and violent recidivism.

The question, however, is to what extent intervention programs have been successful in reducing recidivism and to what extent any changes in pro-criminal attitudes (e.g., MCAA) could be taken as evidence of the effectiveness of said rehabilitation program. For example, Mulder et al. (2012) reported that groups identified as intervention in their study appeared to be worse after going through the program and the rates of recidivism showed no significant pattern between intervention and no intervention groups. Others have argued that the effectiveness of a rehabilitation program may require a more in-depth methodological approach in the format of a mixed method research (Morgan et al., 2019).
The use of mixed methods (research in this area) has been primarily based on the principle of triangulation, employing this as a means of obtaining a more complete picture of the population under study (Morgan et al., 2019; Tonkin-Crine et al., 2016). Existing literature places the significance of mixed methodology in how it offsets the weakness of both quantitative and qualitative methods and provides rich data that would not be possible through either approach alone (Blagden et al., 2016). This has been seen in the evaluation of prison programs (Farrier et al., 2019) who found that while quantitative methods were restricted by limited completion of follow-on questionnaires and concerns regarding response bias, the addition of qualitative interviews revealed the positive impacts on prisoners' mental health and wellbeing. This highlights the benefit of the mixed method approach, as interviews go beyond the quantitative information gained and gather data directly from participants in their own words, indicating the rationale behind the results. Interviews can also be an empowering experience for participants and those who may be reluctant to complete questionnaires or write down their thoughts are often willing to express themselves to an interested, human interviewer.

The main aims of the present study were (a) to examine the effectiveness of engagement in a rugby program training as a rehabilitation program for young male offenders and (b) to utilise both a quantitative and qualitative methodological approach. The quantitative analysis of the effectiveness of the program was assessed on the basis of responses given to the MCAA by those participating in an 8-week intensive rugby program training compared to those that did not and those that did not participate, to assess whether there were differences in pro-criminal attitudes after completing the program. The qualitative analysis of the effectiveness of the program was based on a one to one interview and focus group approach with those that participated in the rugby training program and those that did not, with the aim of assessing their views regarding about criminality, reoffending and the benefits of rugby training in the prison setting.

\section{MATERIALS AND METHODS}

\section{Participants}

In total, 46 young adult males currently serving sentences at the YOI took part in this study. Participants were split into two groups, those in the intervention sample $(\mathrm{n}=25$; mean age, $19.64 \pm$ 0.81 years), and those in the no intervention sample ( $\mathrm{n}=21$; mean age, $19.76 \pm 0.89$ years). Data for the study was collected at three different time cycles of 8 weeks, in May-June $2018(n=18)$, Oc- 
tober-December $2018(\mathrm{n}=8)$, and in May-June $2019(\mathrm{n}=20)$. Additionally, qualitative interviews were carried out with intervention and no intervention groups in May-June $2018(\mathrm{n}=20)$ and with intervention group in October-December 2018 ( $\mathrm{n}=9)$ and a focus group with intervention participants in May-June $2018(\mathrm{n}=12)$ and October-December $2018(\mathrm{n}=15)$.

\section{Materials}

In the present study, the MCAA instrument (Mills et al., 2002) was used to measure criminal attitudes. The selection of this instrument was based on the conceptual concordance with the underpinnings of the intervention, in that it addresses criminal attitudes, values, beliefs and justifications directly related to criminal activity. The use of pre- and postintervention data, specifically change scores (difference between pre- and postintervention test data), are an effective method of determining the degree to which participants benefit from intervention, particularly those taking place in the criminal justice system (Howard and van Doorn, 2018; Simourd et al., 2016).

The MCAA tool was developed by Mills et al. (2002) and consists of two parts: Part A is a quantified self-report measure of criminal friends, and part B is a 46-item measure of attitudes that is composed of four scales: violence (12 items), entitlement (12 items), antisocial intent (12 items), and associates (10 items). The tool is based upon research that has demonstrated that antisocial attitudes and antisocial associates are among the better predictors of antisocial behavior (Mills et al., 2004). The MCAA has been piloted, used and validated with incarcerated adult offenders in Canada. It has shown predictive validity for the outcomes of general and violent recidivism (Mills et al., 2004) and has shown "reasonable reliability (internal consistency and temporal stability) and appropriate convergent and discriminant validity, with criterion validity evidenced in the scale's relationship with criminal history variables, and a factor analysis confirming the four distinct scale domains" (Mills et al., 2002). The temporal stability of the MCAA has also suggested its use as an appropriate pre- and posttest measure for interventions addressing antisocial attitudes.

An abridged version of the MCAA was selected for use in the study, with only part B of the tool administered to participants, with the purpose of assessing attitudes in four key areas: attitudes towards violence, sentiments of entitlement, antisocial intent and attitudes towards associates. It was important for the sample that the questionnaire was accessible and quick to complete due to time constraints, furthermore, and the nature of the sample meant that there was already some suspicion expressed around responding to the statements in the measure. It was concluded that the domain of 'attitudes towards associates' included in part B would be sufficient to measure the level of identification and acceptance of criminal associates, to reflect the influence that criminal associates may have on the individual (Mills et al., 2002).

\section{Procedure}

Ethical approval for this research was granted by Middlesex University Ethics Board and the YOI that participated in the study, through Her Majesty's Prison and Probation Service. The first author began by visiting the prison site and making contact with both the physical education instructors (prison officers who run sports programs, gym sessions, and also function as officers) and the prison governor. Approval from the prison governor for the researcher's access and implications for resource were granted. Single-site permission for the research to take place was then granted in May 2018.

Data collection began in May 2018. The program runs two cycles per year, one in the summer (May-June) and one in the winter (October-November). The first author began by introducing herself to the participants at the start of the intervention program, explaining her role as an external evaluator, informing them about the aims of the research, and what the research process would entail. It was made clear that the research process was separate from the project delivery, independent from the Prison or Probation Services and that participation was entirely voluntary. Information sheets including prison researcher contact details in case of questions or complaints, and an explanation of how to withdraw from the study were given to all participants to keep. All program participants agreed to take part in the research and returned a completed consent form.

\section{Procedure for quantitative data collection}

For the intervention group, the questionnaires were administered to participants at the start of the first week of the intervention and at the end of the final week. These were completed in the classroom. For the no intervention group, questionnaires were administered to participants at the end of the intervention period and were completed on the wing of the prison where they resided. All participants were reassured that their responses would be anonymous and that there was no 'right' or 'wrong' answers. They were all debriefed after taking part in the study.

\section{Procedure for qualitative data collection}

Interviews took place over the second half of the 8-week pro- 
gram. Interviews with participants from intervention and no intervention groups took place in a private office in the prison. Participants were put at ease with informal conversation and assured that although the interview would be recorded for transcribing purposes, their participation would be completely anonymous and they would be identifiable only by a code. They were assured they could take as much time as they needed to respond and if they felt uncomfortable at any time could decline to answer or terminate the interview. The interviews followed a semistructured schedule of 15 guide questions relating to the respondent's time spent in the YOI, views on sport and course participation, self-perception and attitudes towards reoffending and release (a full list of questions included in the schedule are available from the first author upon request). Probes were used in order to gain responses richer in detail if the interviewer felt that the participant had more to say about a topic or could expand on the answers given. The questions in the schedule had to be applicable to both intervention and no intervention groups (with slight modification i.e., "What have you heard about the rugby program?" rather than "How did you hear about the rugby program?"). The interviews lasted between 10 and 50 min and the voice recorder was stopped after the participant had finished responding to the last question. After interview, each participant was thanked for taking part and debriefed, assured their participation was completely voluntary and that any part of their responses could be excluded from data analysis if they wished.

Focus groups also took place in a classroom with intervention participants on the final week of the program. The duration of the focus group was recorded with the permission of the participants. Care was taken by the first author to assure the respondents that they would not be identifiable in any subsequent report, and that the recording would be destroyed afterwards. The first author began the focus group by stating some ground rules including that participants should respect each other's opinion, listen when others were speaking and not repeat any of the discussion elsewhere in the prison. Focus groups followed a semistructure much like the interviews, consisting of six discussion areas and 15 guide ques-

Table 1. Mean total pro-criminal scores and corresponding standard deviations and number of participants as per no intervention and rugby group (preand postintervention)

\begin{tabular}{ll}
\hline Participants & Mean \pm SD \\
\hline No intervention $(n=21)$ & $31.28 \pm 7.69$ \\
Rugby (preintervention) $(n=25)$ & $32.84 \pm 6.70$ \\
Rugby (postintervention) $(n=25)$ & $32.16 \pm 6.00$
\end{tabular}

$\mathrm{SD}$, standard deviation.

Higher rating equals more pro-criminal attitudes. tions in total. Group discussion was prompted on participants' experience of the program, physical activity in prison, rehabilitation, plans for release and what factors would most likely inform and prevent reoffending.

\section{RESULTS}

\section{Quantitative analysis}

\section{No intervention vs. rugby intervention group}

Mean total pro-criminal scores and corresponding standard deviations and number of participants as per no intervention and rugby group (pre- and postintervention) is shown in Table 1.

As can be seen in Table 1 the measures taken from no intervention group do not seem to differ much from the two measures taken from the rugby group at pre- and postintervention comparisons. Indeed, it seems that the rugby group has scored higher at both times from the no intervention group. Independent groups $t$-test comparisons between the no intervention group score and the scores taken at pre and post from the rugby group showed $t(44)=0.73$, $P<0.46$ for total preintervention and no intervention and $t(44)=$ $0.43, P<0.66$ for total postintervention and no intervention group.

\section{Rugby at 2-time measures for all four components}

Mean scores on the MCAA (violence, entitlement, antisocial intent, and associates) and corresponding standard deviations for the rugby groups at pre- and postintervention are shown in Table 2.

As can be seen in Table 2 the measures taken from rugby group do not seem to differ much from the two measures taken at preand postintervention comparisons. Repeated measures $t$-test comparisons showed no significant differences for all four comparisons with $t(24)=0.7, P<0.48$, for violence, $t(24)=0.7, P<0.46$, for entitlement, $t(24)=0.17, P<0.86$ for antisocial intent and $t(24)=$ $0.31, P<0.75$, for associates.

\section{Data collection cycles}

Mean total pro-criminal scores (pre- and postintervention) and

Table 2. Breakdown of pro-criminal attitudes scores as per mean violence, entitlement, antisocial intent and associates measures at pre- and postintervention for the rugby group $(\mathrm{n}=25)$

\begin{tabular}{lcccc}
\hline Intervention & Violence & Entitlement & Antisocial intent & Associates \\
\hline Pre & $7.48 \pm 3.21$ & $7.76 \pm 2.29$ & $9.00 \pm 2.27$ & $8.60 \pm 1.41$ \\
Post & $7.16 \pm 3.13$ & $7.40 \pm 2.64$ & $9.08 \pm 1.77$ & $8.52 \pm 1.53$ \\
\hline
\end{tabular}

Values are presented as mean \pm standard deviation.

The higher the rating the stronger the expressions towards the intended (violence, entitlement, antisocial intent, and associates) measure. 
corresponding standard deviations the rugby groups at 3 cycles of measurement are shown in Table 3.

As can be seen in Table 3 there are differences in measurements between cycle 2 and cycles 1 and 3. One way independent groups analysis of variance for pro-criminal scores at premeasurement between the 3 cycles found $F(2,22)=3.61, \mathrm{MSe}=36.92, P<0.04$ and for postmeasurement $F(2,22)=2.86$, MSe $=31.79, P<0.07$. Post hoc comparisons of the means using Tukey honestly significant difference showed that the mean difference for cycle 2 at preintervention with cycle 3 (mean \pm standard error $[\mathrm{SE}]=7.48 \pm 2.95$ ) is significantly different at $P<0.019$ with lower scores at cycle 2 . Furthermore, the mean difference for cycle 2 at postintervention with cycle 3 (mean $\pm \mathrm{SE}=-6.08 \pm 2.73$ ) is significantly different, at $P<0.03$, with lower scores at cycle 2 .

\section{Qualitative analysis}

Interview data from the intervention and no intervention groups of young adult offenders were transcribed verbatim. Data were analysed using inductive thematic analysis, whereby interesting features of patterns in the text were highlighted, significant and recurring ideas then coded, leading to categories of code and data,

Table 3. Mean total pro-criminal scores pre- and postintervention as per 3 cycles and number of participants per each cycle

\begin{tabular}{lcc}
\hline Cycles & Total preintervention & Total postintervention \\
\hline Cycle $1(n=8)$ & $31.25 \pm 5.67$ & $33.62 \pm 6.11$ \\
Cycle $2(n=8)$ & $29.62 \pm 7.63$ & $28.25 \pm 5.11$ \\
Cycle $3(n=9)$ & $37.11 \pm 4.72$ & $34.33 \pm 5.63$ \\
\hline
\end{tabular}

Values are presented as mean \pm standard deviation. which were reviewed systematically until the most commonly cited concepts were identified. While each theme has been presented and expanded on separately, they are not mutually exclusive. The extracts cited for the purpose of the present study include only a representative sample of participant responses. The themes for each group (intervention and no intervention) indicated by the analysis can be seen in Table 4 with illustrative quotes from transcripts for each theme.

\section{Intervention group themes}

\section{Social cohesion and learning to play together}

The use of team sport to encourage different individuals from across the establishment to mix with each other was perceived as beneficial and values were acquired through playing rugby together as a team such as respect and discipline. Being part of the team provided a behavioral incentive and motivation to achieve, which resulted in observed changes in behavior.

\section{Controlled aggression}

The controlled aggression in rugby was widely emphasized, providing an effective way of releasing anger and stress built up through the prison regime. Working this out on the rugby pitch was seen as a constructive way of resolving tension without consequences.

\section{Positive health behaviors}

Developing a healthy routine and engaging in health behaviors such as going to the gym were perceived to be a positive outcome of taking part in the intervention program, which pushed partici-

Table 4. Themes identified through thematic analysis organised into group and illustrated by examples of quotes from participant transcripts

\begin{tabular}{|c|c|c|}
\hline Group & Theme & Quote \\
\hline \multirow{5}{*}{$\begin{array}{l}\text { Intervention } \\
\text { (rugby) }\end{array}$} & Social cohesion and learning to play together & "The fact that different post codes, we're all together, playing for each other, I think it's really important..." \\
\hline & Controlled aggression & $\begin{array}{l}\text { "So it's good self-control, you can hit someone along the lines of rugby, and they've just gotta walk away. } \\
\text { Same vice versa with you." }\end{array}$ \\
\hline & Positive health behaviors & $\begin{array}{l}\text { "They give you a good structure to a life already, cause you can come out with skills, qualifications, a hobby, } \\
\text { and a routine, which I think is what you need to live a fairly organized and fulfilling life." }\end{array}$ \\
\hline & People around you (associates) & "It's seeing someone else succeed, or someone like, where they've come from change." \\
\hline & Challenges of release and finding support & $\begin{array}{l}\text { "What people say, when you get out, all the plans go away, that's the hardest thing about it, you've got to } \\
\text { really stick to it." }\end{array}$ \\
\hline \multirow[t]{4}{*}{ No intervention } & Inevitability of crime & "I knew, even when I was on road, doing what I was doing, I knew there was a time I would come jail..." \\
\hline & Lack of support & $\begin{array}{l}\text { "Literally, they just put you into the big, bad world to fend for yourself. And that's why I think like a lot of } \\
\text { youths feel hard done by. I feel like that- I felt like that." }\end{array}$ \\
\hline & Financial incentives & $\begin{array}{l}\text { "If you've got older in the area, making money... driving flash cars, being with like loads of girls and stuff, } \\
\text { you wanna get some of that as well." }\end{array}$ \\
\hline & Role models & $\begin{array}{l}\text { "If you see people around you that are going towards crime and less people are going towards the normal } \\
\text { life... then you're gonna just think "oh that's just—I guess that's the way." }\end{array}$ \\
\hline
\end{tabular}


pants to better their fitness and wellbeing.

\section{People around you}

The behavior of friends was perceived to be a predictor of offending behavior with the awareness of needing to cut ties upon release. The needs of a close family member and the positive influence of new friends were deemed to be protective factors that could discourage recidivism.

\section{Challenges of release and finding support}

Resettlement challenges including housing and employment concerns were perceived to be a potential barrier to rehabilitation. Having support systems available upon release were considered an important factor in preventing reoffending however participants identified barriers for seeking emotional support such as the perception of weakness.

\section{No intervention group themes \\ Inevitability of crime}

Participants perceived it to be inevitable to engage in criminal behavior. They similarly considered the consequences that would follow such as prison time, injury or even death as inevitable and these outcomes appeared to be an accepted part of committing crime.

\section{Lack of support}

Participants identified the lack of support and opportunities in their local community as a factor that influenced their criminal activity. If support was not found in the home or community, it was found in other settings that may be conducive to crime, such as a gang.

\section{Financial incentives}

The incentive of money was identified as a key factor in becoming involved in criminal activity. The risks that came with fast money were often perceived to be preferable to the struggle of a minimum wage job, especially when paired with the temptations of a flashy lifestyle demonstrated by older peers in the local area.

\section{Role models}

Male role models found in the local area who could offer guidance and security were identified as a risk factor for involvement in criminal activity, as they represented an aspirational lifestyle that participants wanted to emulate.

\section{DISCUSSION}

The main aim of the present study was to examine the effectiveness of a rugby intervention program as a useful tool for rehabilitation for young male offenders applying both a quantitative and qualitative methodological approach. MCAA measures were taken as evidence of the effectiveness of the program and the data were subjected to quantitative analysis. The results showed no significant change in pro-criminal attitudes before and after the rugby training program. Indeed, there were indications that the no intervention group scored lower on the MCAA measures compared to the pre- and post-MCAA measured of the intervention group. Another interesting finding was the significant differences in the time of data collection on the responses given to MCAA by the intervention group. The qualitative analysis of the effectiveness of the program, however which was based on one to one interviews and focus group discussions, showed a positive improvement in pro-criminal attitudes for those in the rugby intervention program. In what follows the present findings are discussed together with the limitations and implications of the current research.

The expectation was that those involved in the rugby intervention group would score significantly lower at postintervention in pro-criminal attitudes measure than preintervention. However, this was not the case neither for the total measures (Table 1) nor for the breakdown of each sub scale (Table 2). Interestingly, the intervention group had higher (although not significant) pro-criminal attitude scores than the no intervention group. Possible explanations for such a finding could be seen in the kind of personality traits that attracts a person to engage in an overtly aggressive sport such as rugby. As taking part in the rugby program was on a voluntary basis it seems that it has already attracted those with more thrill seeking, sensation seeking personality traits than those that are less likely to engage in such extreme sporting activities. As Cohen et al. (2018a) have demonstrated those engaged in extreme sports differ significantly from those engaged in nonextreme sport (e.g., archery) in showing more robust personality traits. Indeed, Cohen et al. (2018b) further argued that such personality difference may have implications for any rehabilitation intervention. Future researchers should take into account personality makeup of the participants when using psychometric measures in assessing effectiveness of rehabilitation program as a result of extreme sport intervention (e.g., rugby). Reliance on participant's responses to questionnaires alone may thus not be the most beneficial method of assessing effectiveness of intervention programs.

Whilst pre-post intervention measures showed no significant 
differences it was interesting to note that the cycle (time of the year) that participants completed the pro-criminal measures were significantly different between cycle's 1 and 2 and cycle's 2 and 3 (Table 3). Recent research both in psychiatric wards and prison settings has raised the issue of the significance of environmental factors and the timing of any intervention as a factor affecting the outcomes of any intervention treatments (Jaspers et al., 2019). Stasch et al. (2018) argued that the prison climate has a significant effect on prisoner rehabilitation effectiveness. During periods when relationships between prisoners and staff are more positive there are more positive attitudes towards any treatments and interventions. The result of the present study and differences inthe scores of MCAA during the 3-time cycles may be an indication of climate change in the prison affecting participants' responses.

\section{Qualitative}

\section{Social influences and cohesion through rugby}

The expectation was that the intervention participants would have a more positive view of their future and their associations. Both the intervention and the no intervention groups acknowledged the influence of friends on their criminal behavior and gang involvement (Evans et al., 2016; Lenzi et al., 2015). However, the intervention group brought about discussion of cutting ties with old friends in favor of making new, positive friends who could be used as peer role models (Hoge et al., 1996). In addition, the program had fostered a sense of belonging amongst the intervention participants and began considering the effect their imprisonment had on their family, with strong family ties recognized as an important factor in promoting effective resettlement (Walker et al., 2017).

In contrast, the no intervention group showed a lack of sense of belonging and commented on the lack of support in their community. As a consequence, they had found value in a gang setting due to the financial support, protection and sense of belonging it provided (Lenzi et al., 2015; Merrin et al., 2015) and their need for a male role model to provide guidance (Hurd et al., 2009). One explanation for these differences is that the team setting of rugby provided a sense of belonging and team membership for the intervention participants, whilst the no intervention participants found this sense of belonging in gang membership. This is consistent with research that has studied the potential for team sports to bring people together (Thorpe et al., 2014), especially those who are at risk of gang-affiliation (Spruit et al., 2018) with the positive relationship between a good support system and wellbeing well documented (Battaglia et al., 2013).
The intervention group also discouraged gang-related divides in the prison, by facilitating socialization between prisoners and providing an opportunity for conflict resolution. The fostering of this social team environment was also found to be beneficial for participants' behavior as they were held accountable due to their status as a member of the team, with the sport providing an incentive to succeed and a framework for participants to pin their behavior on (Perkins and Noam, 2007).

\section{Risk and protective factors}

Risk factors on release from prison were established by both groups of participants. The crucial time period of resettlement for predicting reoffending is well established (Dickson and Polaschek, 2014) and employment, housing and financial difficulties are key risk factors for young people newly released from prison (Yukhnenko et al., 2019). Unlike the no intervention group, participants of the intervention acknowledged barriers to seeking support, such as the image of masculinity (Kupers, 2005) and the perception of weakness in engaging in help-seeking behaviors (Seidler et al., 2016). Intervention participants also appeared to frame these factors in a more positive light and discussed potential coping mechanisms. A possible explanation for this could be that they felt they had acquired protective factors against reoffending via engagement in the intervention program. These protective factors have been seen in previous research to have a significant effect on reducing reoffending (Rennie and Dolan, 2010). Coping mechanisms established by the intervention group included the controlled aggression of playing rugby which provided a productive and controlled way of releasing tension. The humbling nature of being tackled to the ground has been seen to be particularly crucial in building values such as self-control and resilience (Patience et al., 2013) and full-contact sport has been found to enforce discipline and boundaries (Blomqvist Mickelsson, 2019; Twemlow and Sacco, 1998). The intervention also brought forward the development of positive health behaviors, with it facilitating a daily routine. Participants reported benefits to their fitness and wellbeing, consistent with previous research that suggests an association between team sport and improved health outcomes (Eime et al., 2013) and the benefits of keeping inmates busy and occupied in meaningful pursuits (Wilkinson and Caulfield, 2017).

Protective factors were not acquired by no intervention participants and this, compounded with the motivations they discussed for their involvement in criminal activity, paint a concerning picture. The motivation of gaining 'fast money' through criminal activity as a means to affording an aspirational lifestyle modeled by 
older peer models on the street, carried risk. However, the acceptance of the inevitable consequences (i.e., prison, injury, or death) tied to their engagement with crime is consistent with existing literature which has looked at increased risk-taking behaviors for offenders (Pachur et al., 2010). The contrast between the two groups here highlights the potential for the intervention in providing protective factors that can combat such acknowledged risk factors and discourage participants from considering crime as an 'inevitable' activity. It also suggests the value of using role models in rehabilitation, particularly those with the same lived experience (Haddad et al., 2011; Yancey et al., 2011) that could demonstrate a preference for positive behaviors and choices.

In summary, the findings herein are not without certain limitations. This study questions whether quantitative measures are reliable or sufficient enough in evaluating such prison-based interventions. Research has suggested that self-reported change in antisocial attitudes may not provide valid information about change in risk of recidivism as a result of intervention (Howard and van Doorn, 2018) and therefore other methods may be more beneficial in predicting whether interventions will truly 'rehabilitate' their participants. Similar studies have discovered that while quantitative measures may not reveal a significant difference in change scores, qualitative interviews reveal benefits of the intervention which would otherwise not be seen (Farrier et al., 2019). This emphasizes the need for mixed methods in this research area which has been suggested in previous literature (Blagden et al., 2016).

Qualitative measures allow participants to talk sincerely and express what they really think and thus may be a more accurate measure of the effectiveness of the intervention (Giacomini and Cook, 2000). The specific population of young adult male offenders may also play a role in the effectiveness of the quantitative measure as their social context may explain socially desirable responding to such measures (Howard and van Doorn, 2018), and may influence the truthfulness or accuracy of their answers. Existing studies have encountered similar issues here with response bias, where participants ticked all answers or left questionnaires incomplete (Farrier et al., 2019).

The relatively small sample size of young adult males recruited from the YOI is an additional limitation and this may have been reflected in not only the quantitative data, but in the themes identified through thematic analysis. This was, however, unavoidable due to the nature of the sample population and consequent access challenges. This led to limitations in the matching of the no intervention sample, which is often par for the course in this specific research context (Ramluggun et al., 2010). Similar challenges have been encountered for example by Skerfving et al. (2014) who redesigned their randomized control trial as a quasi-experimental control group study due to unwillingness presented by practitioners to randomize participants into the no intervention group.

\section{Conclusion, implications, and future research}

While not presented in the quantitative results, the positive benefits of taking part in the intervention program were seen through qualitative measures, including the protective factors developed through the team and full-contact setting of rugby. The identified risk factors and motivations for crime also provide implications for improved through the gate support for outside agencies and the prison estate. Although there were no significant differences seen in self-reported pro-criminal attitudes as a result of participating in the rugby intervention, there were significant differences in pro-criminal attitudes at baseline depending on the time of year that the intervention was administered (winter vs. summer). This provides implications for the prison estate and external partners when planning sport interventions, for when they may be most successful in their rehabilitation efforts. The present study has also provided implications for future research in this area. Those using quantitative measures as the sole method in evaluating similar sport interventions should proceed with caution, as valuable improvements in attitudes could be missed. Qualitative methods, in combination with quantitative or on their own, empower participants in this population and provide them with the opportunity to express themselves sincerely.

\section{CONFLICT OF INTEREST}

No potential conflict of interest relevant to this article was reported.

\section{REFERENCES}

Amtmann J, Kukay J. Fitness changes after an 8-week fitness coaching program at a regional youth detention facility. J Correct Health Care 2016;22:75-83.

Bailey R. Physical education and sport in schools: a review of benefits and outcomes. J Sch Health 2006;76:397-401.

Battaglia C, di Cagno A, Fiorilli G, Giombini A, Fagnani F, Borrione P, Marchetti M, Pigozzi F. Benefits of selected physical exercise programs in detention: a randomized controlled study. Int J Environ Res Public Health 2013;10:5683-5696.

Blagden N, Winder B, Hames C. "They treat us like human beings" - ex- 
periencing a therapeutic sex offenders prison: impact on prisoners and staff and implications for treatment. Int J Offender Ther Comp Criminol 2016;60:371-396.

Blomqvist Mickelsson T. Modern unexplored martial arts - what can mixed martial arts and Brazilian Jiu-Jitsu do for youth development? Eur J Sport Sci 2019 Jun 16:1-8 [Epub]. https://doi.org.10.1080/17461391.2019 .1629180 .

Cohen R, Baluch B, Duffy LJ. Defining extreme sport: conceptions and misconceptions. Front Psychol 2018a;9:1974.

Cohen R, Baluch B, Duffy LJ. Personality differences amongst drag racers and archers: implications for sport injury rehabilitation. J Exerc Rehabil 2018b;14:783-790.

Dickson SR, Polaschek DL. Planning to avoid risk or planning for a positive life: the relationship between release plan valence and reoffending. Int J Offender Ther Comp Criminol 2014;58:1431-1448.

Eime RM, Young JA, Harvey JT, Charity MJ, Payne WR. A systematic review of the psychological and social benefits of participation in sport for children and adolescents: informing development of a conceptual model of health through sport. Int J Behav Nutr Phys Act 2013;10:98.

Elbe AM, Wikman JM, Zheng M, Larsen MN, Nielsen G, Krustrup P. The importance of cohesion and enjoyment for the fitness improvement of 8-10-year-old children participating in a team and individual sport school-based physical activity intervention. Eur J Sport Sci 2017;17: 343-350.

Evans SZ, Simons LG, Simons RL. Factors that influence trajectories of delinquency throughout adolescence. J Youth Adolesc 2016;45:156-171.

Farrier A, Baybutt M, Dooris M. Mental health and wellbeing benefits from a prisons horticultural programme. Int J Prison Health 2019;15: 91-104.

Giacomini MK, Cook DJ. Users' guides to the medical literature: XXIII. Qualitative research in health care A. Are the results of the study valid? Evidence-Based Medicine Working Group. JAMA 2000;284:357-362.

Haddad E, Chen C, Greenberger E. The role of important non-parental adults (VIPs) in the lives of older adolescents: a comparison of three ethnic groups. J Youth Adolesc 2011;40:310-319.

Hoge RD, Andrews DA, Leschied LW. An investigation of risk and protective factors in a sample of youthful offenders. J Child Psychol Psychiatry 1996;37:419-424.

Howard MVA, van Doorn G. Within-treatment change in antisocial attitudes and reoffending in a large sample of custodial and community offenders. Law Hum Behav 2018;42:321-335.

Hurd NM, Zimmerman MA, Xue Y. Negative adult influences and the protective effects of role models: a study with urban adolescents. J Youth Adolesc 2009;38:777-789.

Jaspers SØ, Jakobsen LM, Gadegaard CA, Dyreborg J, Andersen LPS,
Aust B. Design of a tailored and integrated violence prevention program in psychiatric wards and prisons. Work 2019;62:525-541.

Kupers TA. Toxic masculinity as a barrier to mental health treatment in prison. J Clin Psychol 2005;61:713-724.

Kwon SJ. A relationship between personality and empathy in teenagers' school sports club participation. J Exerc Rehabil 2018;14:746-757.

Lenzi M, Sharkey J, Vieno A, Mayworm A, Dougherty D, Nylund-Gibson K. Adolescent gang involvement: the role of individual, family, peer, and school factors in a multilevel perspective. Aggress Behav 2015;41: 386-397.

Meek R, Lewis G. The role of sport in promoting prisoner health. Int J Prison Health 2012;8:117-130.

Merrin GJ, Hong JS, Espelage DL. Are the risk and protective factors similar for gang-involved, pressured-to-join, and non-gang-involved youth? A social-ecological analysis. Am J Orthopsychiatry 2015;85:522-535.

Mills JF, Anderson D, Kroner DG. The antisocial attitudes and associates of sex offenders. Crim Behav Ment Health 2004;14:134-145.

Mills JF, Kroner DG, Forth AE. Measures of Criminal Attitudes and Associates (MCAA): development, factor structure, reliability, and validity. Assessment 2002;9:240-253.

Mills JF, Kroner DG, Hemmati T. Predicting violent behavior through a static-stable variable lens. J Interpers Violence 2003;18:891-904.

Moore B, Woodcock S, Dudley D. Developing wellbeing through a randomised controlled trial of a martial arts based intervention: an alternative to the anti-bullying approach. Int J Environ Res Public Health 2018;16:E81.

Morgan SA, McCausland BMS, Parkes J. Baseline characteristics and outcomes of the main perpetrator programme within the Hampshire Domestic Abuse Prevention Partnership, UK: a mixed methods study. PLoS One 2019;14:e0218408.

Mulder E, Vermunt J, Brand E, Bullens R, van Marle H. Recidivism in subgroups of serious juvenile offenders: different profiles, different risks? Crim Behav Ment Health 2012;22:122-135.

Pachur T, Hanoch Y, Gummerum M. Prospects behind bars: analyzing decisions under risk in a prison population. Psychon Bull Rev 2010;17: 630-636.

Patience MA, Kilpatrick MW, Sun H, Flory SB, Watterson TA. Sports game play: a comparison of moderate to vigorous physical activities in adolescents. J Sch Health 2013;83:818-823.

Perkins DF, Noam GG. Characteristics of sports-based youth development programs. New Dir Youth Dev 2007;(115):75-84, 8-9.

Proctor SL, Hoffmann NG, Allison S. The effectiveness of interactive journaling in reducing recidivism among substance-dependent jail inmates. Int J Offender Ther Comp Criminol 2012;56:317-332.

Ramluggun P, Lindsay B, Pfeil M. Research in prison: a researcher-practi- 
tioner's view. Nurse Res 2010;17:60-71.

Rennie CE, Dolan MC. The significance of protective factors in the assessment of risk. Crim Behav Ment Health 2010;20:8-22.

Seidler ZE, Dawes AJ, Rice SM, Oliffe JL, Dhillon HM. The role of masculinity in men's help-seeking for depression: A systematic review. Clin Psychol Rev 2016;49:106-118.

Simourd DJ, Olver ME, Brandenburg B. Changing criminal attitudes among incarcerated offenders: initial examination of a structured treatment program. Int J Offender Ther Comp Criminol 2016;60:1425-1445.

Skerfving A, Johansson F, Elgán TH. Evaluation of support group interventions for children in troubled families: study protocol for a quasi-experimental control group study. BMC Public Health 2014;14:76.

Spruit A, van der Put C, van Vugt E, Stams GJ. Predictors of intervention success in a sports-based program for adolescents at risk of juvenile delinquency. Int J Offender Ther Comp Criminol 2018;62:1535-1555.

Stasch J, Yoon D, Sauter J, Hausam J, Dahle KP. Prison climate and its role in reducing dynamic risk factors during offender treatment. Int J Offender Ther Comp Criminol 2018;62:4609-4621.

Thorpe A, Anders W, Rowley K. The community network: an Aboriginal community football club bringing people together. Aust J Prim Health 2014;20:356-364.

Tonkin-Crine S, Anthierens S, Hood K, Yardley L, Cals JW, Francis NA, Coenen S, van der Velden AW, Godycki-Cwirko M, Llor C, Butler CC, Verheij TJ, Goossens H, Little P; GRACE INTRO/CHAMP consortium. Discrepancies between qualitative and quantitative evaluation of randomised controlled trial results: achieving clarity through mixed methods triangulation. Implement Sci 2016;11:66.

Twemlow SW, Sacco FC. The application of traditional martial arts practice and theory to the treatment of violent adolescents. Adolescence 1998;33:505-518.

Walker A, Kazemian L, Lussier P, Na C. The role of family support in the explanation of patterns of desistance among individuals convicted of a sexual offense. J Interpers Violence 2017 Jun 1:886260517712273 [Epub]. https://doi.org/10.1177/0886260517712273.

Walters GD. Incremental validity of the psychological inventory of criminal thinking styles as a predictor of continuous and dichotomous measures of recidivism. Assessment 2005;12:19-27.

Warner C, Conley T, Murphy R. Criminal thinking shifts among male prisoners participating in a cognitive-based education programme. Crim Behav Ment Health 2018;28:152-157.

Whited WH, Wagar L, Mandracchia JT, Morgan RD. Partners or partners in crime? The relationship between criminal associates and criminogenic thinking. Int J Offender Ther Comp Criminol 2017;61:491-507.

Wilkinson DJ, Caulfield LS. The perceived benefits of an arts project for health and wellbeing of older offenders. Eur J Psychol 2017;13:16-27.

Yancey AK, Grant D, Kurosky S, Kravitz-Wirtz N, Mistry R. Role modeling, risk, and resilience in California adolescents. J Adolesc Health 2011;48:36-43.

Yukhnenko D, Blackwood N, Fazel S. Risk factors for recidivism in individuals receiving community sentences: a systematic review and metaanalysis. CNS Spectr 2019 Jun 20:1-12 [Epub]. https://doi.org/10.1017/ S1092852919001056. 